\title{
Protein tyrosine kinase 6 promotes ERBB2-induced mammary gland tumorigenesis in the mouse
}

\author{
M Peng ${ }^{1}$, SM Ball-Kell ${ }^{1}$ and AL Tyner*1
}

Protein tyrosine kinase 6 (PTK6) expression, activation, and amplification of the PTK6 gene have been reported in ERBB2/HER2positive mammary gland cancers. To explore contributions of PTK6 to mammary gland tumorigenesis promoted by activated ERBB2, we crossed Ptk6 ${ }^{-1}$ mice with the mouse mammary tumor virus-ERBB2 transgenic mouse line expressing activated ERBB2 and characterized tumor development and progression. ERBB2-induced tumorigenesis was significantly delayed and diminished in mice lacking PTK6. PTK6 expression was induced in the mammary glands of ERBB2 transgenic mice before tumor development and correlated with activation of signal transducer and activator of transcription 3 (STAT3) and increased proliferation. Disruption of PTK6 impaired STAT3 activation and proliferation. Phosphorylation of the PTK6 substrates focal adhesion kinase (FAK) and breast cancer anti-estrogen resistance 1 (BCAR1; p130CAS) was decreased in Ptk $6^{-1-}$ mammary gland tumors. Reduced numbers of metastases were detected in the lungs of $P t \mathrm{~K}^{-1}-$ mice expressing activated ERBB2, compared with wild-type ERBB2 transgenic mice. PTK6 activation was detected at the edges of ERBB2-positive tumors. These data support roles for PTK6 in both ERBB2-induced mammary gland tumor initiation and metastasis, and identify STAT3, FAK, and BCAR1 as physiologically relevant PTK6 substrates in breast cancer. Including PTK6 inhibitors as part of a treatment regimen could have distinct benefits in ERBB2/HER2-positive breast cancers.

Cell Death and Disease (2015) 6, e1848; doi:10.1038/cddis.2015.210; published online 6 August 2015

Breast cancer remains the second leading cause of death for women in the United States. ${ }^{1}$ The $20-30 \%$ incidence of overexpression of the epidermal growth factor receptor family tyrosine kinase ERBB2 (HER2, Neu) in breast cancer ${ }^{2,3}$ has made it a prominent therapeutic target. ${ }^{4}$ ERBB2 signaling depends on its heterodimerization with another ERBB family member, often ERBB3 or ERBB1 (epidermal growth factor receptor), which leads to activation of the phosphoinositide 3kinase-AKT pathway. The ERBB2 monoclonal antibody trastuzumab (Herceptin) is an established therapeutic option, but de novo and acquired therapeutic resistance to trastuzumab is an important clinical problem. ${ }^{5}$ Variations among signaling proteins present downstream of ERBB2 can contribute to the development of resistance to trastuzumab and other drugs targeting the ERBB2 pathway.

The intracellular tyrosine kinase PTK6 (also called BRK for Breast tumor kinase) is an intracellular tyrosine kinase that is evolutionarily related to SRC family kinases. ${ }^{6}$ PTK6 is overexpressed in a majority of human breast cancers and in most breast tumor cell lines. $^{7-10}$ Previously, we detected PTK6 expression in a normal mammary gland human breast tissue array, as well as in a human breast tumor array using immunohistochemistry. Phosphorylation of tyrosine residue 342 in the PTK6 activation loop promotes its activation. Interestingly, active PTK6 was only detected in human breast tumors, suggesting that PTK6 may have kinase-independent functions in normal human breast tissue that are distinct from its cancer-promoting activities at the membrane. ${ }^{9}$

A significant correlation between expression of PTK6 and ERBB2 (HER2) has been reported in breast tumors. Several studies have indicated that PTK6 and ERBB2 are coexpressed in human breast tumors and PTK6 promotes ERBB2 oncogenic signaling in human breast tumor cell lines. ${ }^{11-14}$ PTK6 was not detected in the normal mouse mammary gland, but we found that it was induced and activated in mouse mammary gland tumors, including those that developed in mouse mammary tumor virus (MMTV)-ERBB2 transgenic mice. ${ }^{15}$ Previously identified substrates of PTK6 that have been shown to participate in ERBB2 oncogenic signaling include the transcription factor signal transducer and activator of transcription 3 (STAT3), ${ }^{15,16}$ focal adhesion kinase (FAK), ${ }^{17}$ and breast cancer anti-estrogen resistance 1 (BCAR1 also known as p130CAS). ${ }^{18}$

Our group previously generated a Ptk6 null mouse model and characterized its phenotype in the gastrointestinal tract $^{19-21}$ and skin, ${ }^{22}$ tissues where PTK6 is expressed in differentiated epithelial cells. Disruption of Ptk6 led to increased growth and impaired differentiation in the small intestine. $^{21}$ However, when Ptk6 was induced in small intestinal crypt progenitor cells following DNA damage, loss of Ptk6 impaired DNA-damage-induced apoptosis. ${ }^{20}$ Interestingly, although PTK6 has roles in promoting differentiation and apoptosis in normal epithelia, it can also promote

\footnotetext{
Department of Biochemistry and Molecular Genetics, University of Illinois at Chicago, Chicago, IL, USA

${ }^{*}$ Corresponding author: AL Tyner, Department of Biochemistry and Molecular Genetics, University of Illinois College of Medicine, M/C 669, 900 South Ashland Avenue, Chicago 60607, IL, USA. Tel: +312 996 7964; Fax: +312 413 0353; E-mail: atyner@uic.edu

Abbreviations: PTK6, Protein tyrosine kinase 6; BRK, Breast tumor kinase; MMTV, mouse mammary tumor virus; STAT3, signal transducer and activator of transcription 3; FAK, focal adhesion kinase; BCAR1, breast cancer anti-estrogen resistance 1; B2; Ptk6 ${ }^{+/+}$, MMTV-ERBB2 transgenic mouse with wild-type Ptk6; B2; Ptk6 ${ }^{-1}$ ${ }^{-}$, Ptk6 ${ }^{-}$MMTV-ERBB2 transgenic mouse

Received 27.4.2015; revised 22.6.2015; accepted 30.6.2015; Edited by R Aqeilan
} 
tumorigenesis in both the colon and skin. Disruption of Ptk6 led to resistance to azoxymethane/dextran sodium sulfateinduced tumorigenesis in colon ${ }^{19}$ and impaired UVB-induced tumorigenesis in the skin. ${ }^{22}$ These data demonstrate that PTK6 has context-specific functions that differ depending on tissue and cell type.

Here we explored the impact that disrupting Ptk6 has on mammary gland tumorigenesis in the MMTV-ERBB2 mouse model. We found that PTK6 promotes ERBB2-induced tumorigenesis and disruption of Ptk6 in vivo leads to inhibition of STAT3 in pre-tumorigenic mammary glands, and decreased FAK and BCAR1 phosphorylation and activation in mammary gland tumors. Our findings indicate that the induction of PTK6 in ERBB2-induced tumors is physiologically significant, and suggest that targeting PTK6 in ERBB2-positive breast tumors could restrain several signaling pathways that have critical roles in ERBB2-induced tumorigenesis.

\section{Results}

Disruption of Ptk6 impairs ERBB2-induced mammary gland tumorigenesis. Previously, we reported expression and activation of PTK6 in mammary gland tumors that developed in MMTV-ERBB2 transgenic mice. ${ }^{15}$ To determine contributions of PTK6 to ERBB2 tumorigenesis, we crossed MMTV-ERBB2 mice (B2) with $P t k 6^{-/-}$mice that were backcrossed greater than eight generations into the FVB/ NJ strain. No phenotype was detected in the mammary glands of FVB/NJ Ptk6 ${ }^{-/-}$mice; morphology of ducts and alveoli appeared normal and no lactation defects were observed. Three lines of virgin female MMTV-ERBB2 transgenic mice with different Ptk6 genotypes were maintained (B2;Ptk $6^{+/+}$, B2;Ptk6 $6^{+-}$, and B2;Ptk6 ${ }^{-1}$ ). Palpable mammary gland tumors could be detected in some B2;Ptk $6^{+/+}$ animals by 180 days, and by day 210 , all of the B2;Ptk $6^{+/+}$ animals had developed one or multiple tumors $(n=17)$. B2; $\mathrm{Ptk}^{+/-}$mice developed mammary gland tumors later than $\mathrm{B} 2 ; P$ tk $6^{+/+}$animals, and with a lower occurrence and by day $210, \sim 25 \%$ of the B2; $P t k 6^{+-}$animals remained tumor free. However, all B2; $P$ tk ${ }^{+/}$mice developed palpable tumors by day $240(n=16)$.

Complete disruption of Ptk6 markedly delayed tumor initiation. In contrast to $\mathrm{B} 2 ; P \mathrm{tk} 6^{+/+}$and $\mathrm{B} 2 ; P t \mathrm{k} 6^{+/-}$animals, no tumors were detected in any of the B2;Ptk $\sigma^{-/-}$animals by day $210(n=20) .92 \%$ of $\mathrm{B} 2 ; P t k 6^{-/-}$animals remained tumor free up to 240 days, in contrast to all of the Ptk6-expressing mice that had developed mammary gland tumors. By 260 days, $58 \%$ of the B2; $P$ tk $6^{-/-}$animals remained tumor free, whereas all $\mathrm{B} 2 ; P$ tk $6^{+/+}$mice had reached humane end points and mice were killed. The average time required for detection of palpable mammary gland tumors was 184, 201, and 306 days for $P t k 6^{+/+}, P t k 6^{+/-}$, and $P t k 6^{-/-}$, respectively. Some B2; $P t k 6^{-/-}$animals remained tumor free for 1 year. Although most B2;Ptk ${ }^{-1}$ mice developed breast tumors after 12 months, tumor initiation was significantly delayed and the survival time was increased. B2; Ptk $6^{+/+}$animals were maintained until they reached the humane end point (tumor $>2 \mathrm{~cm}$ ). B2;Ptk $6^{-/-}$animals were killed at later time points when tumor burden (mass) was similar to the B2;Ptk6 ${ }^{+/+}$mice for analyses of tumors and tumor metastasis.

Kinetics of mammary tumor onset in $P$ tk $6^{+/+}, \mathrm{PtkG}^{+/-}$, and Ptk6 ${ }^{-/}$/MMTV-ERBB2 virgin female mice is shown in Figure 1a. Tumor growth in three representative MMTVERBB2 littermates with different Ptk6 genotypes at 260 days of age is shown in Figure 1b. These data demonstrate that systemic disruption of Ptk6 results in a dramatic reduction in ERBB2-induced tumorigenesis in vivo.

PTK6 promotes proliferation and STAT3 activation in MMTV-ERBB2 transgenic mammary glands before tumor development. PTK6 protein is not detectable in normal mammary gland epithelial cells of nontransgenic mice throughout development (Figure 2a). However, strong PTK6 expression was detected in ERBB2-positive mammary glands (Figure 2b), which corresponded with increased proliferation measured by examining the Ki-67-labeling index using immunohistochemistry (Figures $2 \mathrm{c}$ and $\mathrm{d}$ ). These data indicate that PTK6 expression is induced downstream of ERBB2, and that PTK6 promotes ERBB2-regulated cell proliferation in the mammary gland.

PTK6 activity was measured in MMTV-ERBB2 transgenic mouse mammary glands by examining phosphorylation of tyrosine residue 342 (P-Y342) in the PTK6 activation loop, which serves as a marker for its activation. ${ }^{23}$ Data from two different pairs of mice at age 120 days and 150 days are shown in Figure 2e. Active PTK6 was localized at the membrane in mammary gland epithelial cells, and was only detected in wildtype MMTV-ERBB2 mice demonstrating the specificity of the

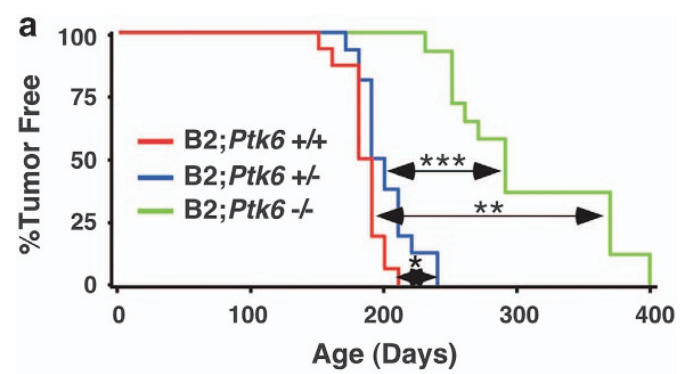

b

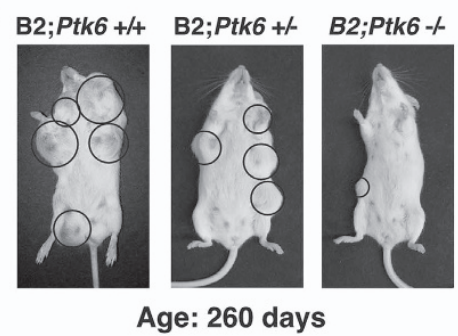

Figure 1 Loss of PTK6 expression delays MMTV-ERBB2-induced mammary gland tumor formation in mice. (a) Female MMTV-ERBB2 mice with different Ptk6 genotypes (B2;Ptk ${ }^{+/+} ; \mathrm{B} 2 ; P t k 6^{+-}-\mathrm{B} 2 ; P t k 6^{-/}$) displayed distinct mammary gland tumor formation kinetics. $P$-values: ${ }^{*} P=0.01$ and ${ }^{* *},{ }^{* *} P<0.001$ between groups indicated by arrows; $n=17$ (B2; Ptk $\left.{ }^{+/+}\right) ; n=16\left(\mathrm{~B} 2 ; \mathrm{Ptk}^{6^{+-}}\right) ; n=20\left(\mathrm{~B} 2 ; \mathrm{Ptk}^{-1-}\right)$. (b) Three littermates with different $P$ tk 6 genotypes displayed different tumor burdens at 260 days of age because of differences in the timing of tumor initiation. Mammary gland tumors are circled 


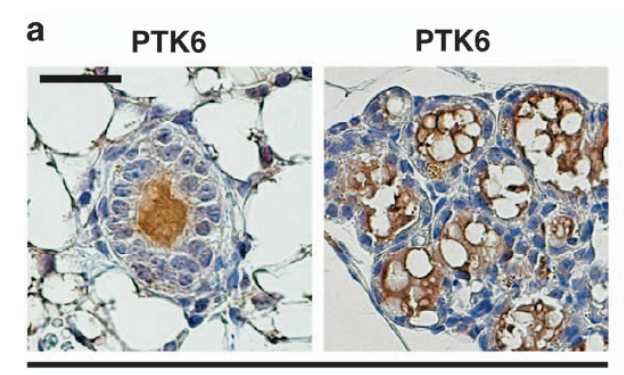

Nontransgenic $\begin{array}{lll}\text { b } & \text { ERBB2 } & \text { PTK6 }\end{array}$

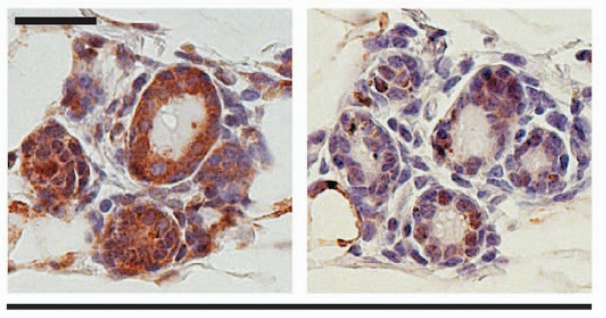

MMTV-ERBB2

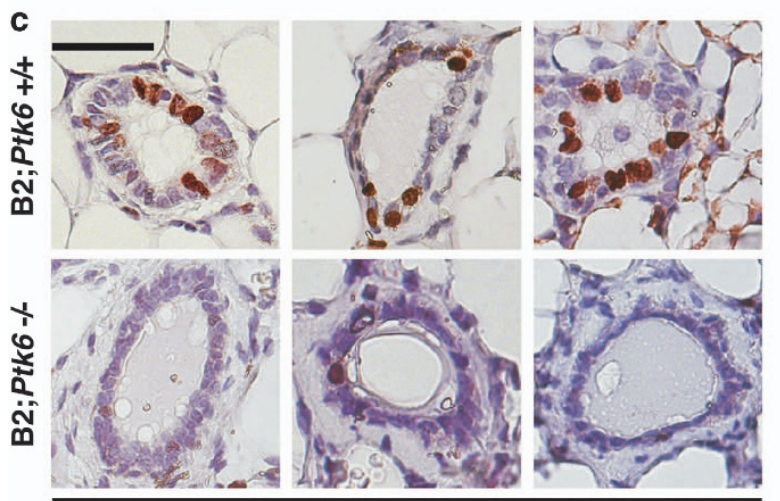

Ki-67

e

B2; Ptk6 +/+
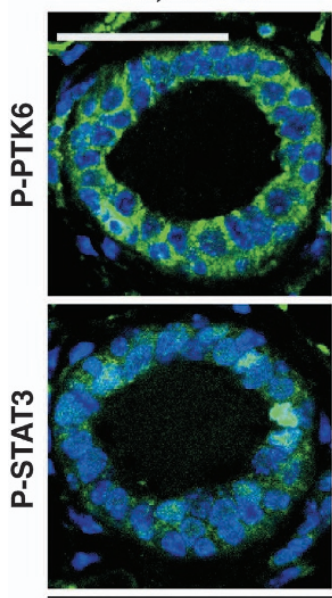

B2;Ptk6 --
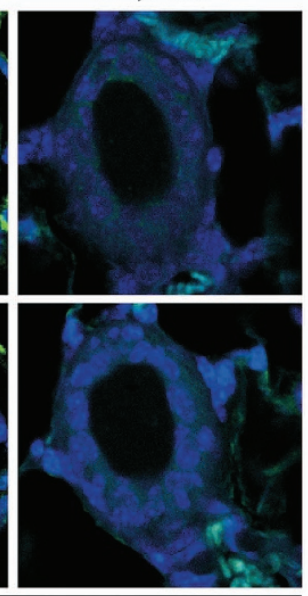

120 Days d

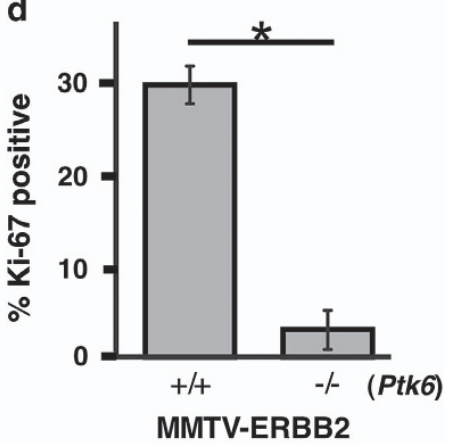

B2;Ptk6 --
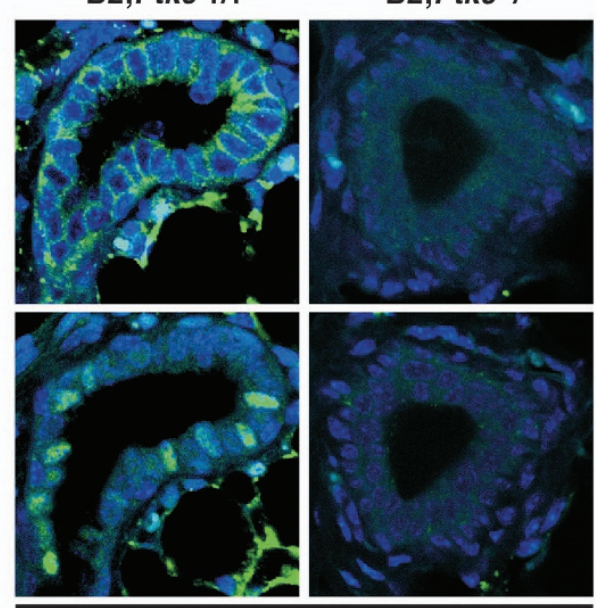

150 Days

Figure 2 PTK6 expression is induced in pre-tumorigenic MMTV-ERBB2 mammary glands and promotes STAT3 activation and proliferation. (a) PTK6 was not expressed in wild-type mouse mammary glands in the mature animals, regardless of the developmental states of the glands (left panel, normal virgin mammary gland; right panel, lactating mammary gland). The brown signal in the center of the glands does not include the epithelial cells and represents background. (b) PTK6 expression is induced by ectopic ERBB2. ERBB2 and PTK6 are coexpressed in epithelial cells of a 5-month-old MMTV-ERBB2 PTK6 transgenic mouse. (c) Proliferation is impaired in MMTV-ERBB2-positive mammary glands following disruption of Ptk6. Proliferation in pre-tumorigenic mammary gland epithelial cells was examined by Ki-67 staining. Each panel represents a different animal. (d) Proliferation in mammary gland epithelial cells was quantified by normalizing Ki-67-positive epithelial cells to the total number of epithelial cells. Each group contains five animals, and five different random views were counted per animal. The difference in percent of Ki67-positive cells in B2;Ptk ${ }^{+/+}(28.5 \%)$ and B2;Ptk $6^{-/-}(2.8 \%)$ is statistically significant ( ${ }^{*} P<0.001$ ). (e) Active PTK6 (P-Y342) and active phospho-STAT3 (PY705) can be detected in the same areas in the B2; Ptk6 ${ }^{+/+}$mammary glands. In contrast, active phospho-STAT3 was not detectable in B2;Ptk6 ${ }^{-1-}$ animals. The size bars represent $50 \mu \mathrm{m}$

antibody for PTK6. STAT3 activation requires phosphorylation at tyrosine residue 705 in its carboxyl terminus, and this residue has been identified as a substrate for PTK6. ${ }^{16}$ Immunofluorescence staining of serial sections revealed increased levels of active phospho-STAT3 in mammary gland epithelial cells with increased expression and activation of PTK6 (Figure 2e).

In contrast to the pre-tumorigenic mammary gland, STAT3 activation and proliferation were not reproducibly higher in well-established Ptk6 ${ }^{+/+}$MMTV-ERBB2 tumors (Figures 3a 


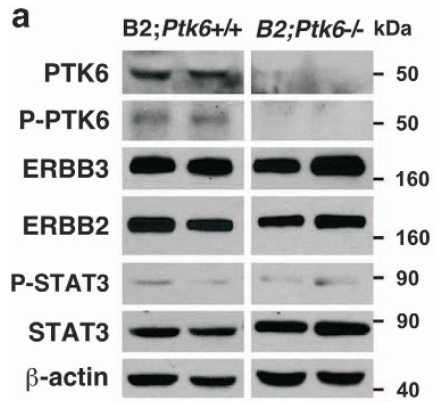

C
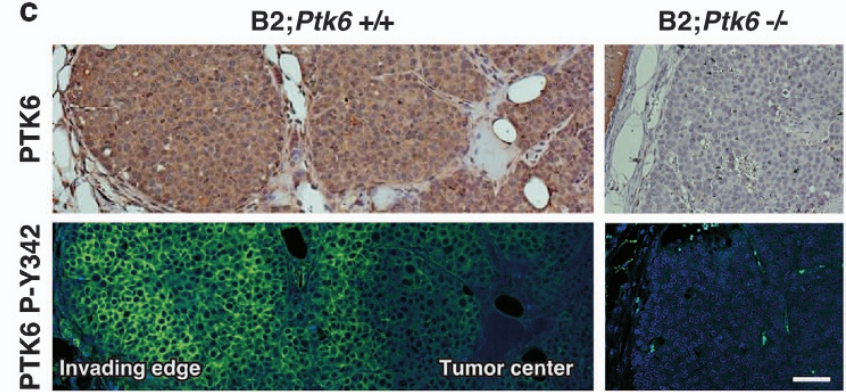

b

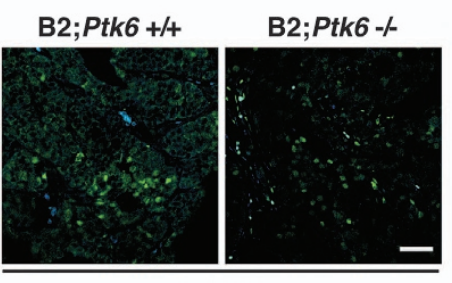

d $\quad B 2 ; P t k 6+1+\quad B 2 ;$ Ptk6 -l-

P-STAT3

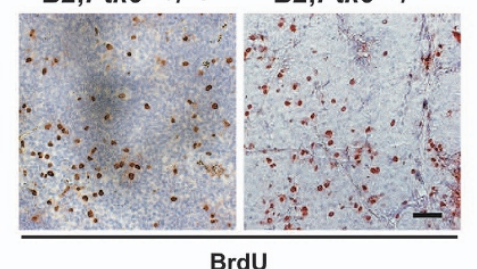

Figure 3 PTK6 is induced throughout ERBB2-induced tumors, but it is activated primarily at the invading edges. (a) Protein lysates from ERBB2 transgenic mammary gland tumors were subjected to immunoblotting. Expression of total and active PTK6 was detected only in B2;Ptk6 ${ }^{+/+}$lysates. Active P-STAT3 levels were not significantly different between B2;Ptk $6^{++}$and B2;Ptk6 ${ }^{-1-}$ animals. (b) Cells with active P-STAT3 were detected in B2;Ptk6 ${ }^{+/+}$and B2;Ptk $6^{-1-}$ tumors. Although heterogeneous staining could be detected within tumors, a significant difference in the number of P-STAT3-positive cells was not observed. (c) Total PTK6 is ubiquitously expressed in ERBB2 mammary gland tumors as shown by immunohistochemistry, but active PTK6 was primarily localized to the invading edges of the tumors but not in the center. Panels on the right are controls that demonstrate mammary gland tumors that developed in B2;Ptk ${ }^{-l-}$ mice are negative for total and active PTK6. (d) BrdU incorporation in breast tumors from B2;Ptk6 ${ }^{+/+}$and B2; $P t k 6^{-I-}$ animals with similar tumor burden was examined by immunohistochemistry. The size bars represent $50 \mu \mathrm{m}$

and b). STAT3 activation was examined by immunoblotting (Figure 3a) and immunohistochemistry (Figure 3b). Comparable levels of P-STAT3 were detected by immunoblotting in both genotypes, and P-STAT3-positive nuclei could be detected in $\mathrm{PtkG}^{+/+}$and $P$ tk6 ${ }^{-1-}$ tumors. Active P-PTK6 was detected in Ptk $\sigma^{+/+}$but not in Ptk6 ${ }^{-/-}$tumors, as expected (Figures 3a and c). Although total PTK6 protein levels were distributed throughout the mammary gland tumors, activation of PTK6 was detected most strongly at the edges of the tumors (Figure 3c). BrdU incorporation into breast tumors was not significantly different and tumor size did not vary significantly between $P t k G^{+/+}$and $P t k 6^{-1-}$ mice, from the time of the initial tumor palpation until the humane end point (Figure 3d). These data suggest that the PTK6 may be more important for mammary gland tumor initiation rather than growth, or its effect on proliferation could be masked by other strong driver oncogenes like ERBB2 itself.

PTK6 regulates tyrosine phosphorylation of FAK and BCAR1 and metastasis of mammary gland tumors to the lung. Recent studies identified $F A K^{17}$ and $B C A R 1^{18}$ as direct PTK6 substrates. Both FAK and BCAR1 have been shown to have important roles in ERBB2-regulated tumorigenesis and metastasis in mouse models. Therefore, we examined FAK and BCAR1 expression and tyrosine phosphorylation in $\mathrm{Ptk}^{+/+}$and PtkG ${ }^{-1}$ MMTV-ERBB2 transgenic mice. Comparable expression of FAK was detected in mammary gland tumors that formed in $P t k G^{++}$and $P t k \sigma^{-/-}$ MMTV-ERBB2 transgenic mice, but activating tyrosine phosphorylation of FAK at tyrosine residues 576/577 was impaired in Ptk6 ${ }^{-1-}$ tumors (Figure 4a). Similarly, BCAR1 expression was detected in both genotypes, but phosphorylation of the BCAR1 substrate domain at tyrosine residue 165 was impaired in Ptk6 ${ }^{\prime-}$ tumors (Figure $4 \mathrm{~b}$ ). Interestingly, both phospho-FAK and phospho-BCAR1 were concentrated near the edge of the tumors, corresponding with active P-PTK6 localization (Figure 3c). These data indicate that PTK6 has an important functional role in regulating both FAK and BCAR phosphorylation in mammary gland tumors in vivo.

To examine tumor metastasis, we collected lung tissues from Ptk $^{+/+}$and $P$ tk $6^{-1-}$ MMTV-ERBB2 transgenic mice with similar total tumor burden, which included mice aged $243 \pm 15$ days $\left(P t k 6^{+/+}\right)$and $364 \pm 33$ days $\left(P t k 6^{-/-}\right)$. Multiple intravascular (tumor emboli) and parenchymal (primarily mammary gland carcinoma, solid type) masses were quantified and normalized to the area of normal lung tissue in tissue sections (Figure $5 \mathrm{a}$ ). The percent metastases (area of lung occupied by neoplastic mammary gland epithelial cells) was significantly lower in Ptk ${ }^{/-}$lungs than in $P$ tk $\sigma^{+/+}$lungs (Figure 5b). Active PTK6 was detected in lung tumor nodules, but a significant decrease in Ki67 was not detected in Ptk6 ${ }^{-/-}$ lung metastases, suggesting that although PTK6 promotes primary tumor metastasis, its activation does not contribute to proliferation in metastatic lesions.

\section{Discussion}

ERBB2 is overexpressed in $~ 30 \%$ of human breast tumors and this correlates with a worse prognosis and clinical outcome. ${ }^{3,24}$ PTK6 is expressed and activated ${ }^{9}$ in human breast tumors that overexpress ERBB2. We show that PTK6 contributes to both tumor initiation and metastasis in the MMTV-ERBB2 mouse model of breast cancer. We previously showed that PTK6 expression is induced in MMTV-ERBB2 
a $\quad$ B2;Ptk6+/+

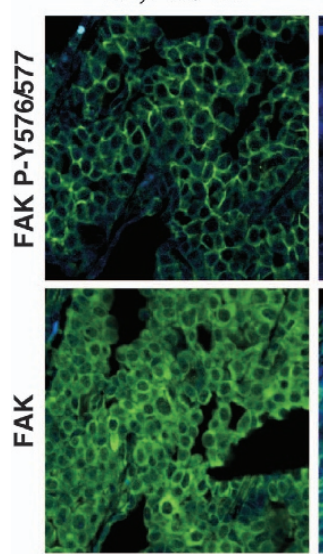

B2;Ptk6 \%
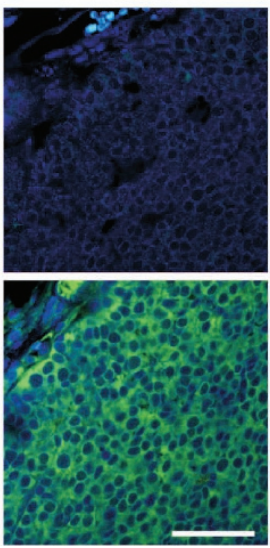

b

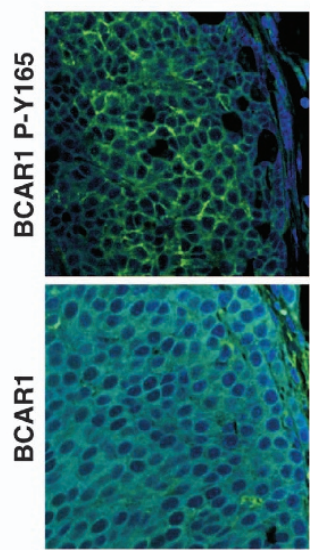

B2;Ptk6 -

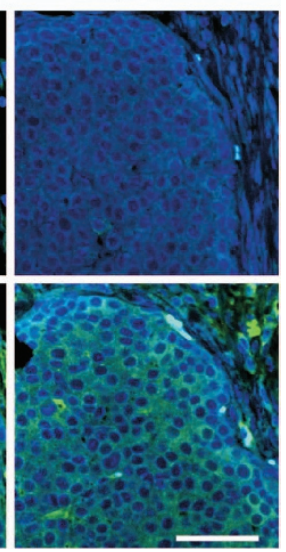

Figure 4 Disruption of Ptk6 impairs tyrosine phosphorylation of FAK and BCAR1 in ERBB2-positive mammary gland tumors. (a) Activated FAK (P-Y576/577) and total FAK expression were examined in MMTV-ERBB2-positive mammary gland tumors. Disruption of Ptk6 gene led to dramatically reduced levels of activated FAK phosphorylated at tyrosine residues 576/577. (b) Phosphorylated BCAR1 (P-Y165) and total BCAR1 expression were examined in MMTV-ERBB2-positive mammary gland tumors. Disruption of Ptk6 led to reduced phosphorylation of BCAR1. Both P-FAK and P-BCAR1 were primarily localized to the invading edges of the tumors, matching the expression pattern of P-PTK6 (Figure 3c). The size bars represent $50 \mu \mathrm{m}$

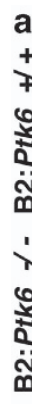

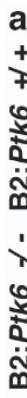
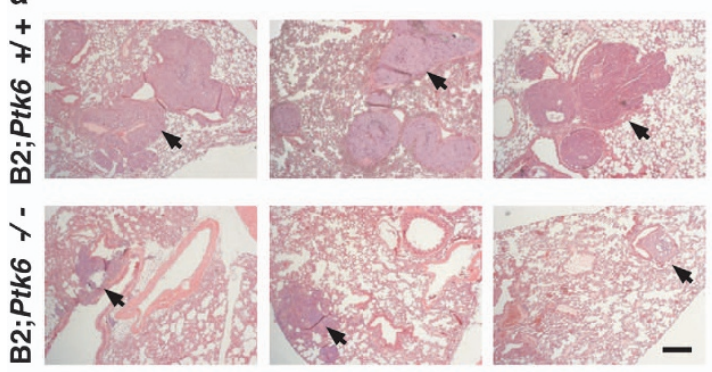

C

B2; Ptk6 +l+
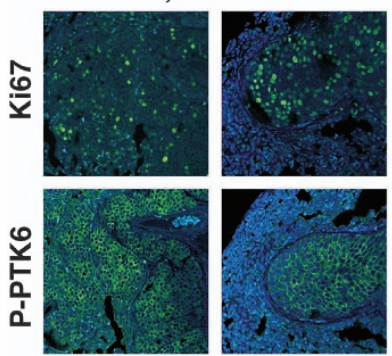

b

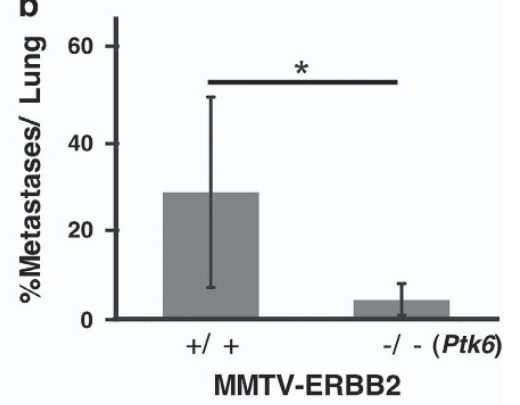

Figure 5 Disruption of Ptk6 impairs mammary gland tumor metastasis to the lung. (a) Lung sections from six B2;Ptk $6^{+/+}$and six B2;Ptk6 $6^{-1-}$ animals with similar tumor burden and similar-sized primary tumors were stained with hematoxylin and eosin, and data from three different representative pairs are shown. Fewer intravascular (tumor emboli) and parenchymal masses (arrows) were detected in B2;Ptk6 $6^{-1}$ lungs. Representative sections are shown for each animal. The size bar represents $200 \mu \mathrm{m}$. (b) Contributions of metastases to total lung tissue were quantified. B2;Ptk6 ${ }^{+/+}: n=9, \mathrm{~B} 2 ; \mathrm{Ptk}^{-1-}: n=6$. ${ }^{*} P$-value $=0.013$. (c) Activating phosphorylation of PTK6 is detected in the metastatic tumor nodules/emboli in the lungs, although proliferation as measured by Ki-67 staining was not statistically different between $\mathrm{B} 2 ; \mathrm{Ptk}^{+/+}$and B2;Ptk6 ${ }^{-1-}$ mice. Sections from two different animals from each group are shown. The size bar represents $50 \mu \mathrm{m}$

transgenic mouse mammary gland tumors, ${ }^{15}$ and here we demonstrate that PTK6 expression can be detected in the mammary glands of these mice before tumor development. A recent study found that ERBB2 can promote PTK6 protein stability through negative regulation of calpain, a calciumdependent, non-lysosomal cysteine protease, in breast cancer cell lines. ${ }^{25}$ PTK6 expression is also regulated at the transcriptional $^{26}$ and post transcriptional ${ }^{27}$ levels by HIF-1a. $\mathrm{HIF}-1$ expression is positively regulated by ERBB2, ${ }^{28}$ and it is required for ERBB2-mediated mammary gland tumor growth. ${ }^{29}$

PTK6 promotes activating phosphorylation of STAT3 at tyrosine residue $705 .{ }^{16}$ In a previous study, STAT3 activation was detected in MMTV-PTK6 transgenic mouse mammary glands but not in control nontransgenic mammary glands, supporting a role for PTK6 in promoting STAT3 activation. ${ }^{15}$ Here, our data suggest that the initial induction of PTK6 in the ERBB2-positive mouse mammary gland has a distinct role in 
promoting STAT3 activation and epithelial cell proliferation in the pre-tumorigenic mammary gland (Figure 2). Before mammary gland tumor formation, activating phosphorylation of STAT3 was detected in mammary glands of MMTV-ERBB2 transgenic mice expressing PTK6, but not in ERBB2-positive $P t k 6^{-1-}$ mammary glands, and this correlated with higher numbers of Ki-67-positive cells (Figure 2). However, we could not detect reproducible quantifiable differences in STAT3 activation or mammary gland epithelial cell proliferation in established Ptk $^{+/+}$and Ptk6 ${ }^{-/-}$ERBB2-positive tumors (Figure 3).

STAT3 has been shown to promote tumor initiation of different tumor types, including those of the gastrointestinal tract and skin (reviewed in refs ${ }^{30,31,32}$ ), and PTK6 was previously shown to promote STAT3 activation and tumorigenesis in mouse models of colon and skin cancer. ${ }^{19,22}$ We show that mammary tumor latency is increased in Ptk6 ${ }^{-1-}$ MMTV-ERBB2 mice (Figure 1), and our studies suggest that PTK6-mediated regulation of STAT3 activation promotes ERBB2-induced mammary gland tumor initiation. STAT3 has been shown to contribute to mammary gland tumor progression and metastasis in established mouse models, ${ }^{33,34}$ and activation of STAT3 has been detected in human breast cancer stem cell models. ${ }^{35}$

We found that disruption of Ptk6 resulted in reduced metastasis of similar-sized primary tumors to the lungs when comparing $\mathrm{Ptk}^{+/+}$and Ptk6 ${ }^{-/-}$MMTV-ERBB2 transgenic mice (Figure 5). PTK6 can have an impact on tumor progression and metastasis through its regulation of FAK and BCAR1. FAK is an intracellular tyrosine kinase that is overexpressed and/or activated in several types of cancers with established roles in regulating tumor progression and metastasis. ${ }^{36}$ We determined that $P$ tk $6^{+/+}$MMTV-ERBB2 mice exhibited increased levels of active FAK, phosphorylated on tyrosine residues 576/577 (Figure 4a). Disruption of the geneencoding FAK in the mouse mammary gland blocked mammary gland tumor progression, ${ }^{37}$ but did not appear to be required for tumor induction ${ }^{38}$ in ERBB2 transgenic mice. Conditional disruption of FAK in MMTV-PyMT transgenic mice led to delayed and reduced tumor formation and suppression of tumor progression. ${ }^{39}$

We detected impaired phosphorylation of BCAR1 at tyrosine 165 in its substrate domain in ERBB2-induced mammary gland tumors with disruption of Ptk6 (Figure 4b). BCAR1 is a scaffold protein that promotes protein-protein interactions and regulates aspects of cell migration, proliferation, and apoptosis. It has an essential role during early development, and has also been implicated in promoting tumorigenesis. BCAR1 was identified in a screen for genes that confer breast tumor resistance to anti-estrogens. ${ }^{40}$ Transgenic expression of BCAR1 in the MMTV-ERBB2 mouse model led to shorter latency of tumor formation compared with expression of ERRB2 alone. ${ }^{41}$ Knockdown of BCAR1 impaired cell migration and invasion of cells expressing active ERBB2. ${ }^{42}$ Phosphorylation of tyrosine residues in the BCAR substrate domain provides docking sites for signaling proteins and has been implicated in promoting migration and cell survival. ${ }^{43,44}$ We previously determined that tyrosine residues in the BCAR1 substrate domain can be phosphorylated by PTK6, and that BCAR1 was important for oncogenic signaling in prostate cancer cells. ${ }^{18}$
Several studies with human tumor cell lines have suggested PTK6 contributes to ERBB2-induced breast cancer. A recent study showed that siRNA mediated knockdown of both PTK6 and ERBB2 in human breast cancer cell lines additively impairs xenograft tumor growth. ${ }^{45}$ Recently, PTK6 was identified as a kinase that is differentially regulated in ERBB2-positive breast cancer cells that develop resistance to lapatinib, $^{46}$ and shRNA mediated knockdown of PTK6 reduced growth and promoted apoptosis of lapatinibresistant ERBB2-positive breast cancer cell lines. ${ }^{47}$ For the first time, we have established that endogenous wild-type PTK6 signaling contributes to ERBB2-induced mammary gland tumorigenesis and metastasis in vivo in a mouse model of ERBB2-induced breast cancer. We have determined that PTK6 promotes tumor initiation and progression and is important for regulation of STAT3, FAK, and BCAR1. Disruption of Ptk6 significantly delayed and reduced ERBB2-induced mammary gland tumor formation and metastasis, providing strong rationale for therapeutically targeting PTK6 alone or in combination with other agents in ERBB2/HER2-positive breast cancers.

\section{Materials and methods}

Mice. Ptk6 null mice (B6-Ptk6 $6^{\text {tm1Aty }}$ ) in the C57BL/6 strain $^{19}$ were backcrossed with the FVB/N inbred strain (Harlan Laboratories, Frederick, MD, USA) for at least eight generations to generate Ptk6 null mice in FVB/N background. FVB-Ptk $6^{\text {tm1Aty }}$ were then crossed with FVB-MMTV-ERBB2 transgenic mice ${ }^{48}$ (Jackson Laboratories, Bar Harbor, ME, USA, Stock number 005038, FVB-Tg(MMTVErbb2) ${ }^{\mathrm{NK} 1 \mathrm{Mu} / \mathrm{J}}$ ) to produce ERBB2;Ptk6 ${ }^{-1-}$ animals. These mice carry activated rat c-Neu (Erbb2) (Val ${ }^{664}$ to $\left.\mathrm{Glu}^{664}\right)$ under the control of the MMTV long-terminal repeat (LTR).

Tissues from age-matched female mice were used in all experiments, and FVB/NJ nontransgenic mice were used for maintaining the lines and nontransgenic controls. Animals were palpated one or two times a week for subcutaneous mass from the age of 8 weeks.

Tissue preparation and analysis. Mammary gland tissues were harvested from sexually mature female animals aged from 4 to 6 months at the estrus/ metestrus phase, to control for hormonally regulated changes in proliferation. ${ }^{49}$ The phase of the estrus cycle was determined by vaginal smear. ${ }^{50}$ Mammary gland tumors were harvested when the animals reached the criteria for humane end points. Tissues were fixed in 10\% buffered formalin (Fisher Scientific, Pittsburgh, PA, USA) for $24 \mathrm{~h}$ and then transferred to $70 \%$ ethanol before processing. Paraffinembedded tissues were sectioned at $5 \mu \mathrm{m}$ and stained with antibodies and then counterstained with hematoxylin. Mammary gland tumor sections were evaluated by a veterinary pathologist (S M Ball-Kell).

For metastatic lung tumors, lungs from at least six animals per genotype were harvested and embedded in paraffin. Lungs were then serially sectioned at $500 \mu \mathrm{m}$ intervals and three slides from each animal were stained with hematoxylin and eosin for histopathologic evaluation. The metastatic nodules present in five photographic images were randomly selected from each slide and quantified. The relative sizes of the lung metastases were measured by Image $J^{51}$ and normalized to the area of normal lung tissue. Owing to the uneven distribution of metastatic tumors in the lung, the slides for each animal with the highest number of metastatic lung nodules/normal lung tissue ratio were compared.

Analysis of protein expression. Preparation of protein lysates and immunoblotting, immunohistochemistry, and immunofluorescence staining were performed as previously described. ${ }^{15}$ Anti-mouse PTK6 (C-17), anti-ERBB2, antiERBB3, and anti-FAK antibodies were purchased from Santa Cruz Biotechnology (Santa Cruz, CA, USA). Antiphospho-PTK6 Tyr-342 (P-Y342) antibody was purchased from Millipore (Bedford, MA, USA). Total STAT3 and phospho-STAT3 PY705, phospho-FAK P-Y576/577, and phospho-BCAR1 P-Y165 antibodies were purchased from Cell Signaling Technology (Danvers, MA, USA). Anti-BCAR1 antibody was obtained from BD Bioscience (San Jose, CA, USA), and anti-Ki-67 
antibody from Abcam (Cambridge, MA, USA). Anti $\beta$-actin (AC-15) was purchased from Sigma-Aldrich (St Louis, MO, USA). Sheep anti-mouse and donkey anti-rabbit antibodies were purchased from GE Healthcare Biosciences (Pittsburgh, PA, USA).

Statistics. For Figure 1a, survival analysis was used to estimate and compare the distributions of time to tumor formation. Three groups of mice with the genotypes of $\mathrm{B} 2 ; \mathrm{PtkG}^{+/+}, \mathrm{B} 2 ; \mathrm{Ptk}^{+/-}$, and $\mathrm{B} 2 ; \mathrm{Ptk}^{-/-}$were plotted for KaplanMeier survival curves. Statistical analysis was conducted using the survival analysis package PROC LIFETEST in the software SAS 9.3 (SAS, Cary, NC, USA). P-values from log-rank tests for comparing survival curves were generated and a difference was considered statistically significant if the $P$-value was equal to or less than 0.05 . For Figures $2 \mathrm{~d}$ and $5 \mathrm{~b}$, quantitative data are shown as the mean \pm S.D. $P$-values were determined using the two-tailed Student's $t$-test (Microsoft Excel, 2010).

\section{Conflict of Interest}

The authors declare no conflict of interest.

Acknowledgements. AL Tyner is supported by NIH grant RO1 DK044525 and an award from the Elsa U Pardee Foundation. We thank Dr. Hui Xie in the UIC Design and Analysis Core for assistance with statistics, and Ms. Priya Mathur for providing helpful comments and editing the manuscript.

\section{Author contributions}

MP: acquisition of data, analysis and interpretation of data, drafting the manuscript. SMB-K: acquisition of data and analysis and interpretation of data (Veterinary Pathologist). ALT: design, analysis and interpretation of data, drafting the manuscript.

1. ACS. Cancer Facts \& Figures 2014. In: American Cancer Society: Atlanta, 2014.

2. Konecny G, Pauletti G, Pegram M, Untch M, Dandekar S, Aguilar Z et al. Quantitative association between HER-2/neu and steroid hormone receptors in hormone receptorpositive primary breast cancer. J Natl Cancer Inst 2003; 95: 142-153.

3. Slamon DJ, Godolphin W, Jones LA, Holt JA, Wong SG, Keith DE et al. Studies of the HER-2/neu proto-oncogene in human breast and ovarian cancer. Science 1989; 244 707-712.

4. Jones KL, Buzdar AU. Evolving novel anti-HER2 strategies. Lancet Oncol 2009; 10: $1179-1187$

5. Pohlmann PR, Mayer IA, Mernaugh R. Resistance to trastuzumab in breast cancer. Clin Cancer Res 2009; 15: 7479-7491.

6. Brauer PM, Tyner AL. Building a better understanding of the intracellular tyrosine kinase PTK6 - BRK by BRK. Biochim Biophys Acta 2010; 1806: 66-73.

7. Barker KT, Jackson LE, Crompton MR. BRK tyrosine kinase expression in a high proportion of human breast carcinomas. Oncogene 1997; 15: 799-805.

8. Irie HY, Shrestha Y, Selfors LM, Frye F, lida N, Wang Z et al. PTK6 regulates IGF-1-induced anchorage-independent survival. PLOS ONE 2010; 5: e11729.

9. Peng M, Emmadi R, Wang Z, Wiley EL, Gann PH, Khan SA et al. PTK6/BRK is expressed in the normal mammary gland and activated at the plasma membrane in breast tumors. Oncotarget 2014; 5: 6038-6048.

10. Ostrander JH, Daniel AR, Lofgren K, Kleer CG, Lange CA. Breast tumor kinase (protein tyrosine kinase 6) regulates heregulin-induced activation of ERK5 and p38 MAP kinases in breast cancer cells. Cancer Res 2007; 67: 4199-4209.

11. Xiang B, Chatti K, Qiu H, Lakshmi B, Krasnitz A, Hicks J et al. Brk is coamplified with ErbB2 to promote proliferation in breast cancer. Proc Natl Acad Sci USA 2008; 105: 12463-12468.

12. Ludyga N, Anastasov N, Gonzalez-Vasconcellos I, Ram M, Hofler H, Aubele M. Impact of protein tyrosine kinase 6 (PTK6) on human epidermal growth factor receptor (HER) signalling in breast cancer. Mol Biosyst 2011; 7: 1603-1612.

13. Ludyga N, Anastasov N, Rosemann M, Seiler J, Lohmann N, Braselmann H et al. Effects of simultaneous knockdown of HER2 and PTK6 on malignancy and tumor progression in human breast cancer cells. Mol Cancer Res 2013; 11: 381-392.

14. Ai M, Liang K, Lu Y, Qiu S, Fan Z. Brk/PTK6 cooperates with HER2 and Src in regulating breast cancer cell survival and epithelial-to-mesenchymal transition. Cancer Biol Ther 2013; 14: 237-245.

15. Peng M, Ball-Kell SM, Franks RR, Xie H, Tyner AL. Protein tyrosine kinase 6 regulates mammary gland tumorigenesis in mouse models. Oncogenesis 2013; 2: e81.

16. Liu L, Gao Y, Qiu H, Miller WT, Poli V, Reich NC. Identification of STAT3 as a specific substrate of breast tumor kinase. Oncogene 2006; 25: 4904-4912.

17. Zheng Y, Gierut J, Wang Z, Miao J, Asara JM, Tyner AL. Protein tyrosine kinase 6 protects cells from anoikis by directly phosphorylating focal adhesion kinase and activating AKT. Oncogene 2013; 32: 4304-4312.

18. Zheng Y, Asara JM, Tyner AL. Protein-tyrosine kinase 6 promotes peripheral adhesion complex formation and cell migration by phosphorylating p130 CRK-associated substrate. J Biol Chem 2012; 287: 148-158.
19. Gierut J, Zheng Y, Bie W, Carroll RE, Ball-Kell S, Haegebarth A et al. Disruption of the mouse protein tyrosine kinase 6 gene prevents STAT3 activation and confers resistance to azoxymethane. Gastroenterology 2011; 141: 1371-1380 e2.

20. Haegebarth A, Perekatt AO, Bie W, Gierut JJ, Tyner AL. Induction of protein tyrosine kinase 6 in mouse intestinal crypt epithelial cells promotes DNA damage-induced apoptosis. Gastroenterology 2009; 137: 945-954.

21. Haegebarth A, Bie W, Yang R, Crawford SE, Vasioukhin V, Fuchs E et al. Protein tyrosine kinase 6 negatively regulates growth and promotes enterocyte differentiation in the small intestine. Mol Cell Biol 2006; 26: 4949-4957.

22. Chastkofsky MI, Bie W, Ball-Kell SM, He YY, Tyner AL. Protein tyrosine kinase 6 regulates UVB-induced signaling and tumorigenesis in mouse skin. $J$ Invest Dermatol 2015; e-pub ahead of print 30 April 2015; doi:10.1038/jid.2015.166

23. Qiu H, Miller WT. Regulation of the nonreceptor tyrosine kinase Brk by autophosphorylation and by autoinhibition. J Biol Chem 2002; 277: 34634-34641.

24. Slamon DJ, Clark GM, Wong SG, Levin WJ, Ullrich A, McGuire WL. Human breast cancer: correlation of relapse and survival with amplification of the HER-2/neu oncogene. Science 1987; 235: 177-182.

25. Ai M, Qiu S, Lu Y, Fan Z. HER2 regulates Brk/PTK6 stability via upregulating calpastatin, an inhibitor of calpain. Cell Signal 2013; 25: 1754-1761.

26. Regan Anderson TM, Peacock DL, Daniel AR, Hubbard GK, Lofgren KA, Girard BJ et al. Breast tumor kinase (Brk/PTK6) is a mediator of hypoxia-associated breast cancer progression. Cancer Res 2013; 73: 5810-5820.

27. Pires IM, Blokland NJ, Broos AW, Poujade FA, Senra JM, Eccles SA et al. HIF-1alphaindependent hypoxia-induced rapid PTK6 stabilization is associated with increased motility and invasion. Cancer Biol Ther 2014; 15: 1350-1357.

28. Laughner E, Taghavi P, Chiles K, Mahon PC, Semenza GL. HER2 (neu) signaling increases the rate of hypoxia-inducible factor 1alpha (HIF-1alpha) synthesis: novel mechanism for HIF-1-mediated vascular endothelial growth factor expression. Mol Cell Biol 2001; 21: 3995-4004.

29. Whelan KA, Schwab LP, Karakashev SV, Franchetti L, Johannes GJ, Seagroves TN et al The oncogene HER2/neu (ERBB2) requires the hypoxia-inducible factor HIF-1 for mammary tumor growth and anoikis resistance. J Biol Chem 2013; 288: 15865-15877.

30. Li N, Grivennikov SI, Karin M. The unholy trinity: inflammation, cytokines, and STAT3 shape the cancer microenvironment. Cancer Cell 2011; 19: 429-431.

31. Grivennikov SI, Karin M. Dangerous liaisons: STAT3 and NF-kappaB collaboration and crosstalk in cancer. Cytokine Growth Factor Rev 2010; 21: 11-19.

32. Pedranzini L, Leitch A, Bromberg J. Stat3 is required for the development of skin cancer. $J$ Clin Invest 2004; 114: 619-622.

33. Ranger JJ, Levy DE, Shahalizadeh S, Hallett M, Muller WJ. Identification of a Stat3dependent transcription regulatory network involved in metastatic progression. Cancer Res 2009; 69: 6823-6830.

34. Barbieri I, Quaglino E, Maritano D, Pannellini T, Riera L, Cavallo F et al. Stat3 is required for anchorage-independent growth and metastasis but not for mammary tumor development downstream of the ErbB-2 oncogene. Mol Carcinog 2010; 49: 114-120.

35. Wei W, Tweardy DJ, Zhang M, Zhang X, Landua J, Petrovic I et al. STAT3 signaling is activated preferentially in tumor-initiating cells in claudin-low models of human breast cancer. Stem Cells 2014; 32: 2571-2582.

36. Sulzmaier FJ, Jean C, Schlaepfer DD. FAK in cancer: mechanistic findings and clinical applications. Nat Rev Cancer 2014; 14: 598-610.

37. Lahlou H, Sanguin-Gendreau V, Zuo D, Cardiff RD, McLean GW, Frame MC et al. Mammary epithelial-specific disruption of the focal adhesion kinase blocks mammary tumor progression. Proc Natl Acad Sci USA 2007; 104: 20302-20307.

38. Lahlou H, Sanguin-Gendreau V, Frame MC, Muller WJ. Focal adhesion kinase contributes to proliferative potential of ErbB2 mammary tumour cells but is dispensable for ErbB2 mammary tumour induction in vivo. Breast Cancer Res 2012; 14: R36.

39. Pylayeva Y, Gillen KM, Gerald W, Beggs HE, Reichardt LF, Giancotti FG. Ras- and PI3Kdependent breast tumorigenesis in mice and humans requires focal adhesion kinase signaling. J Clin Invest 2009; 119: 252-266.

40. Brinkman A, van der Flier S, Kok EM, Dorssers LC. BCAR1, a human homologue of the adapter protein $\mathrm{p} 130 \mathrm{Cas}$, and antiestrogen resistance in breast cancer cells. J Natl Cancer Inst 2000; 92: 112-120.

41. Cabodi S, Tinnirello A, Di Stefano P, Bisaro B, Ambrosino E, Castellano I et al. p130Cas as a new regulator of mammary epithelial cell proliferation, survival, and HER2-neu oncogenedependent breast tumorigenesis. Cancer Res 2006; 66: 4672-4680.

42. Cabodi S, Tinnirello A, Bisaro B, Tornillo G, del Pilar Camacho-Leal M, Forni G et al. p130Cas is an essential transducer element in ErbB2 transformation. FASEB J 2010; 24: 3796-3808.

43. Cunningham-Edmondson AC, Hanks SK. p130Cas substrate domain signaling promotes migration, invasion, and survival of estrogen receptor-negative breast cancer cells. Breast Cancer (Lond) 2009; 1: 39-52.

44. Meenderink LM, Ryzhova LM, Donato DM, Gochberg DF, Kaverina I, Hanks SK. P130Cas Src-binding and substrate domains have distinct roles in sustaining focal adhesion disassembly and promoting cell migration. PLOS ONE 2010; 5: e13412.

45. Falkenberg N, Anastasov N, Hofig I, Bashkueva K, Lindner K, Hofler H et al. Additive impact of HER2-/PTK6-RNAi on interactions with HER3 or IGF-1R leads to reduced breast cancer progression in vivo. Mol Oncol 2015; 9: 282-294. 
46. Stuhlmiller TJ, Miller SM, Zawistowski JS, Nakamura K, Beltran AS, Duncan JS et al. Inhibition of lapatinib-induced kinome reprogramming in ERBB2-positive breast cancer by targeting BET family bromodomains. Cell Rep 2015; 11: 390-404.

47. Park SH, Ito K, Olcott W, Katsyv I, Halstead-Nussloch G, Irie HY. PTK6 inhibition promotes apoptosis of Lapatinib-resistant Her2 breast cancer cells by inducing Bim. Breast Cancer Res 2015; 17: 86.

48. Muller WJ, Sinn E, Pattengale PK, Wallace R, Leder P. Single-step induction of mammary adenocarcinoma in transgenic mice bearing the activated c-neu oncogene. Cell 1988; 54: 105-115.

49. Schedin P, Mitrenga T, Kaeck M. Estrous cycle regulation of mammary epithelial cell proliferation, differentiation, and death in the Sprague-Dawley rat: a model for investigating the role of estrous cycling in mammary carcinogenesis. J Mammary Gland Biol Neoplasia 2000; 5: 211-225.

50. Byers SL, Wiles MV, Dunn SL, Taft RA. Mouse estrous cycle identification tool and images. PLOS ONE 2012; 7: e35538.
51. Rasband WS. ImageJ. US National Institutes of Health: Bethesda, Maryland, USA, 2011, http://imagej.nih.gov/ij/.

(c) (i) Cell Death and Disease is an open-access journal published by Nature Publishing Group. This work is licensed under a Creative Commons Attribution 4.0 International License. The images or other third party material in this article are included in the article's Creative Commons license, unless indicated otherwise in the credit line; if the material is not included under the Creative Commons license, users will need to obtain permission from the license holder to reproduce the material. To view a copy of this license, visit http://creativecommons.org/licenses/by/4.0/ 